\title{
MOPP Regimen
}

National Cancer Institute

\section{Source}

National Cancer Institute. MOPP Regimen. NCI Thesaurus. Code C9619.

A chemotherapy regimen consisting of mechlorethamine, vincristine (Oncovin), procarbazine and prednisone, used alone or in combination with radiation therapy for the treatment of stage I-IV Hodgkin lymphoma. Due to the increased risk of gonadal toxicity, this regimen has been widely replaced by the ABVD regimen. 